\section{Acionando a}

chave de desvio

dos trilhos:

repensando a

história social

do trabalho

ferroviário no

Brasil império

\author{
Marcelo Mac Cord[1]
}

SOUZA, Robério $S$.

Trabalhadores dos trilhos:

imigrantes e nacionais livres, $l i$ -

bertos e escravos na construção

da primeira ferrovia baiana

(1858-1863). Campinas:

Unicamp, 2015. 270 p. Coleção

Várias Histórias, n. 42.

Resenha recebida em 17 de dezembro de 2016 e aprovada para publicação em 19 de dezembro de 2016.

[1] Faculdade de Educação da Universidade Federal Fluminense (UFF) Niterói (RJ) - Brasil.

E-mail: marcelomaccord@gmail.com

DOI: 10.1590/TEM-1980-542X2017v230111
7 rabalhadores dos trilhos: imigrantes e nacionais livres, libertose escravos na construção da primeira ferroviabaiana (1858-1863) é a mais recente obra de Robério Souza. O livro desse talentoso pesquisador, que atualmente é professor do curso de história da Universidade do Estado da Bahia (Uneb), oferece ao leitor uma série de análises das complexidades políticas, econômicas, culturais, sociais e étnicas que envolveram a construção da Bahia and San Francisco Railway. Publicado pela Editora da Unicamp em 2015, o livro, que faz parte da consolidada "Coleção Várias Histórias", baseia-se na premiada tese de doutorado do autor, que, sob a orientação de Silvia Lara, foi defendida dois anos antes no Cecult-IFCH-Unicamp.

O livro Trabalhadores dos trilhos, com suas significativas inovações historiográficas, consolida a carreira de Robério Souza como um dos mais destacados especialistas sobre o mundo do trabalho brasileiro. E ratifica sua importância como historiador do mundo do trabalho ferroviário. Em 2011, pela EDUFBA, o pesquisador baiano publicou outro livro sobre a temática: Tudo pelo trabalho livre: trabalhadores e conflitos no pós-abolição (Bahia, 1892-1909). Nesse trabalho inovador, fruto de sua dissertação de mestrado, o autor analisa os conflitos de classe e de cor naquela mesma ferrovia, mas privilegiou uma temporalidade que nos permite conhecer as lutas dos trabalhadores negros contra formas de trabalho análogas aos tempos da escravidão (Souza, 2011).

Ambas as publicações fazem parte da mais refinada história social de matriz thompsoniana produzida em nosso país. Tal historiografia, absolutamente identificada com a Unicamp, reconhece a importância da agência dos subalternos na condução de suas próprias vidas e de seu protagonismo 
na luta de classes - com desdobramento nas mais variadas lutas dos "de baixo" por direitos jurídicos, sociais, culturais, econômicos e políticos. De forma muito especial, o livro Trabalhadores dos trilhos ainda aponta para a possibilidade de convergências entre a história social da escravidão e a história social do trabalho stricto sensu, dissolvendo, assim, as fronteiras analíticas e temáticas que ainda existem entre elas. ${ }^{2}$

Em sua sólida trajetória acadêmica, Robério Souza não escolheu seus objetos de estudo aleatoriamente ou de forma diletante. Nascido em Alagoinhas, cidade cortada pela antiga Bahia and San Francisco Railway, a vida do autor, oriundo da classe trabalhadora, esteve ligada direta e indiretamente aos trilhos de ferro. Tal peculiaridade ganha ainda mais significado quando sabemos de sua cor preta. A experiência étnica e de classe do pesquisador foram fundamentais em suas investigações, permitindo que seu esforço científico desconstruísse uma historiografia que invisibilizava os negros como protagonistas tanto na construção da primeira estrada de ferro baiana quanto na organização das históricas lutas dos "de baixo" por direitos trabalhistas e sociais.

Do ponto de vista formal, Trabalhadores dos trilhos é um livro muito bem enredado. São cinco capítulos que dialogam entre si, abordando os seguintes temas: implicações político-econômicas da construção da Bahia and San Francisco Railway, engajamento da mão de obra nacional e estrangeira, acordos sobre contratos e arranjos de trabalho, surgimento de alguma consciência de classe nos canteiros de obras da ferrovia e conflitos entre empregados, patrões, encarregados e autoridades públicas. A documentação utilizada é vasta e densa: correspondências governamentais, registros policiais, processos criminais, periódicos, leis, relatórios oficiais, fotografias etc. Todo o material compulsado foi encontrado em arquivos baianos e ingleses.

Logo nas primeiras páginas, Robério Souza demonstra como muitos historiadores e cientistas sociais do século passado, pouco afeitos ao trabalho empírico, se apoiaram acriticamente na legislação imperial que proibia o uso de mão de obra escrava na construção de ferrovias. Aprovada em 1852, a norma acabou induzindo leituras sociologizantes sobre a temática, o que reforçou a explicação de que existiu uma transição teleológica do trabalho escravo para o trabalho livre no Brasil oitocentista. E, nessas sentenças, a ferrovia surgiu como símbolo de "modernização", ou, em outras palavras, como um empreendimento que viabilizou o amadurecimento das relações capitalistas e do mercado de trabalho em nosso país.

No livro, o tradicional consórcio entre "modernização" do mundo do trabalho e construção das ferrovias brasileiras começa a ser desconstruído assim que o autor demonstra a relação umbilical dos ingleses da Bahia and San Francisco Railway e das autoridades locais com o escravismo. Segundo Robério Souza, por exemplo, muitos empreiteiros e técnicos

${ }^{2}$ Sobre as fronteiras entre história social da escravidão e história social do trabalho stricto sensu, consultar Chalhoub e Silva (2009, p. 11-50). 
britânicos compraram e mantiveram cativos em suas próprias casas. Portanto, no cotidiano baiano, era impossível dissociá-los. Para justificar e compreender essa prática, o pesquisador nos remete ao fato de que capitais e homens de negócios ingleses estiveram intimamente envolvidos com o tráfico atlântico ilegal até 1850 - pouco antes da abertura dos canteiros de obras da ferrovia.

As fontes compulsadas por Robério Souza ainda revelam que os profissionais britânicos responsáveis pela construção da Bahia and San Francisco Railway contratavam escravos para os canteiros de obras da ferrovia. Eles alegavam ser impossível identificar a real condição jurídica dos negros que buscavam serviço. De certa forma, em alguns momentos, como salienta o pesquisador, os contratadores poderiam dizer a verdade. Contudo, acostumados com o escravismo e preocupados em viabilizar as empreitadas, pouco se esforçavam para verificar a situação legal das pessoas escravizadas que se passavam por livres. E, aproveitando-se dessa situação, precarizavam ao máximo a força de trabalho dos africanos e de seus descendentes.

Os escravos que se passavam por homens livres, por sua vez, encaravam os serviços oferecidos pela primeira ferrovia baiana como uma possibilidade de se "esconderem" de seus senhores, como propõe Robério Souza. Conseguir um emprego nos trilhos de ferro também era uma forma de os cativos se passarem por homens livres, tendo em vista as determinações impostas pela lei imperial de 1852. Ainda sobre as estratégicas apropriações feitas pelos "de baixo", o autor afirma que a construção da Bahia and San Francisco Railway serviu como forma de esconderijo para outros sujeitos, como criminosos e desertores. Tais indivíduos queriam ficar invisíveis aos agentes da polícia, da justiça, das milícias e das forças militares.

Entre os trabalhadores que estiveram vinculados às rotinas dos canteiros de obras da Bahia and San Francisco Railway, Robério Souza afirma que poucos eram africanos livres (gente ilegalmente traficada da África para o Brasil entre os anos 1831 e 1850) ou “índios”. Nas páginas de Trabalhadores dos trilhos, sobre o primeiro grupo, observamos que alguns grandes proprietários baianos desviavam os "escravos da nação" mais jovens, saudáveis e fortes para suas terras, impedindo que o governo utilizasse essa mão de obra nos canteiros de obras da ferrovia. Para substituí-los, os senhores de terra e de gente mandavam para as empreitadas os cativos mais velhos e alquebrados de sua propriedade.

Além de escravos que se passavam por livres, africanos livres, "índios", criminosos e desertores, a Bahia and San Francisco Railway também contou com a mão de obra do nacional livre. Estes últimos eram referidos pelos contratantes e pelos administradores do empreendimento como "preguiçosos" e "inconstantes". Robério Souza deixa claro que tais julgamentos eram preconceitos étnicos e classistas. Os nacionais livres não aceitavam certas condições de trabalho, rebelavam-se quando injustiçados e tinham na roça seu principal meio de sustento. De acordo com a sazonalidade de seus cultivos e das vantagens financeiras que poderiam auferir, eles conjugavam ou não o plantio de subsistência com os canteiros de obras ferroviários. 
Em meio a tanta gente de pele escura (livre, liberta e escrava) em um empreendimento "moderno" e "modernizador", o operário estrangeiro também se fez presente. Os italianos chegaram à Bahia com a promessa de "moralizar" e "morigerar" os canteiros de obras da Bahia and San Francisco Railway. Apesar de serem os únicos a terem contratos formais de trabalho, também foram explorados pelos contratantes, tendo seus acordos constantemente desrespeitados. Robério Souza, por meio de farta análise documental, demonstra que isso gerou fortes tensões. Uma greve foi deflagrada por causa da insatisfação dos italianos, o que gerou forte repressão e posterior controle policial, com toques de recolher e cerceamento da livre circulação.

Historiador social arguto e sensível, Robério Souza entende a repressão sofrida pelos italianos como mais uma forma de constatarmos os tênues limites entre trabalho escravo e trabalho livre no Brasil império. Sobretudo após a deflagração da greve, os operários europeus da Bahia and San Francisco Railway foram vigiados mais de perto pelas autoridades policiais baianas e por seus patrões. Sob forte ameaça, tinham de seguir rapidamente dos canteiros de obras para seus alojamentos e ficaram com mobilidade limitada em seus momentos de lazer e de descanso. Ao exigirem o devido respeito aos contratos, os italianos experimentaram contratempos muito semelhantes àqueles que foram impostos aos africanos e seus descendentes escravizados.

Como podemos perceber, entre os anos 1858 e 1863, os canteiros de obras da Bahia and San Francisco Railway reuniram os mais variados tipos que viviam do suor do próprio rosto. O livro Trabalhadores dos trilhos chama nossa atenção para essa diversidade social e demográfica. E, mais do que isso, permite que conheçamos as alianças e os conflitos vivenciados pela multidão que construiu a primeira estrada de ferro baiana. Por um lado, como afirma Robério Souza, a precariedade possibilitou alguma consciência de classe: italianos e escravos criaram planos conjuntos de sublevação; as festas e as relações de vizinhança uniam pessoas. Por outro lado, ainda segundo o autor, refluxos ocorreram pelas diferenças de cor, nacionalidade e cultura.

Na construção da Bahia and San Francisco Railway, os fluxos e os refluxos da formação de alguma consciência de classe, processo muito bem analisado por Robério Souza, é um dos pontos altos do livro Trabalhadores dos trilhos. Inspirado por E. P. Thompson, o autor endossa a crítica de que a classe operária é uma construção histórica motivada por certas condições sociais. Portanto, como algo que é forjado na luta, a classe operária não surge pronta e acabada em determinado espaço-tempo, como algo exigido pela necessidade histórica - fruto do devir. O marxista inglês nos ensina que sua construção precisa dialogar com o processo histórico, algo que exige dos analistas especial atenção aos sujeitos, à crítica aos modelos engessados e à empiria. ${ }^{3}$

${ }_{3}^{3}$ Para saber mais, consultar Thompson $(1997,1981)$. 
Por tudo isso, um dos maiores méritos de Trabalhadores dos trilhos é pensar a história social do trabalho sem engessamentos ou isolamentos teóricos. Robério Souza se apropria de instrumentos analíticos e categorias como etnia, classe, nacionalidade, trabalho escravo, trabalho livre e "modernização" sem perder de vista o processo histórico, a ação política dos sujeitos e a relação dos conceitos com sua pesquisa empírica. Ele ainda conseguiu tecer uma potente análise baseada na história social sem descuidar de elementos das histórias política, cultural e econômica. Utilizando a imagem da própria ferrovia, o livro é um entroncamento que nos permite visitar muitas estações da experiência humana. 


\section{Referências bibliográficas}

CHALHOUB, Sidney; SILVA, Fernando T. da. Sujeitos no imaginário acadêmico: escravos e trabalhadores na historiografia brasileira desde os anos 1980. Cadernos AEL, Campinas, v. 14, p. 11-50, 2009.

SOUZA, Robério S. Tudo pelo trabalho livre: trabalhadores e conflitos no pós-abolição (Bahia, 1892-1909). Salvador: EDUFBA; São Paulo: Fapesp, 2011.
THOMPSON, E. P. A formação da classe operária inglesa: a árvore da liberdade. 3. ed. Rio de Janeiro: Paz e Terra, 1997. v. 1.

. A miséria da teoria ou um planetário de erros: uma crítica ao pensamento de Althusser. Rio de Janeiro: Zahar, 1981. 